\title{
Testing measurement equivalence of eudaimonic and hedonic entertainment motivations in a cross-cultural comparison
}

\author{
Odağ, Özen ; Hofer, Matthias ; Schneider, Frank M ; Knop, Katharina
}

\begin{abstract}
Within Hofstede's framework of individualistic and collectivistic cultures, this contribution examines measurement equivalence of hedonic and eudaimonic entertainment motivations in two different cultures, namely Germany representing a more individualistic culture $(\mathrm{N}=180)$ and Turkey representing a more collectivistic culture $(\mathrm{N}=97)$. By means of a multi-group confirmatory factor analysis, we could secure configural invariance for both hedonic and eudaimonic entertainment motivations across the German and Turkish sample. Metric invariance, however, could only be obtained for hedonic, but not for eudaimonic motivations. Scalar invariance was obtained for neither of the two entertainment motivations. The study points to the importance of equivalence testing when conducting cross-cultural research.
\end{abstract}

DOI: https://doi.org/10.1080/17475759.2015.1108216

Posted at the Zurich Open Repository and Archive, University of Zurich

ZORA URL: https://doi.org/10.5167/uzh-132228

Journal Article

Accepted Version

Originally published at:

Odağ, Özen; Hofer, Matthias; Schneider, Frank M; Knop, Katharina (2016). Testing measurement equivalence of eudaimonic and hedonic entertainment motivations in a cross-cultural comparison. Journal of Intercultural Communication, 45(2):108-125.

DOI: https://doi.org/10.1080/17475759.2015.1108216 
Measurement Equivalence of Eudaimonic and Hedonic Entertainment Motivations in a CrossCultural Comparison

\author{
Özen Odă̆ \\ Jacobs University Bremen, Germany \\ Matthias Hofer \\ Michigan State University/University of Zurich, Switzerland \\ Frank M. Schneider \\ University of Mannheim, Germany \\ Katharina Knop \\ University of Mannheim, Germany
}

\title{
Author note:
}

Özen Odağ, Bremen International Graduate School of Social Sciences, Jacobs University; Matthias Hofer, Institute of Mass Communication and Media Research, University of Zurich; Frank M. Schneider, Institute for Media and Communication Studies, University of Mannheim; Katharina Knop, Institute for Media and Communication Studies, University of Mannheim.

Correspondence concerning this article should be addressed to Özen Odağ, Jacobs University, South Hall No. 315 (BIGSSS), Campus Ring 1, 28759 Bremen. E-mail: o.odag@jacobs-university.de

We thank Anne Bartsch for her invaluable comments on earlier versions of this paper as well as the German data set. 
Testing Measurement Equivalence of Eudaimonic and Hedonic Entertainment Motivations in a Cross-Cultural Comparison

\begin{abstract}
Within Hofstede's framework of individualistic and collectivistic cultures, this contribution examines measurement equivalence of hedonic and eudaimonic entertainment motivations in two different cultures, namely Germany representing a more individualistic culture $(N=180)$ and Turkey representing a more collectivistic culture $(N=97)$. By means of a multi-group confirmatory factor analysis (MCFA), we could secure configural invariance for both hedonic and eudaimonic entertainment motivations across the German and Turkish sample. Metric invariance, however, could only be obtained for hedonic, but not for eudaimonic motivations. Scalar invariance was obtained for neither of the two entertainment motivations. The study points to the importance of equivalence testing when conducting cross-cultural research.
\end{abstract}

Keywords: measurement invariance, cross-cultural comparison, collectivistic and individualistic cultures, eudaimonic and hedonic entertainment 
Testing Measurement Equivalence of Eudaimonic and Hedonic Entertainment Motivations in a Cross-Cultural Comparison

Examining and above all securing equivalence across different research objects is a prerequisite for any comparison between two or more cultures (He \& De Vijver, 2012). In other words, to be applicable in different cultural environments, theoretical concepts and their operationalization have to carry the same meaning across the respective cultures, that is, instruments used to assess and compare these concepts across different cultures have to yield the same factor structure across cultures. Without explicitly securing equivalence by means of measurement invariance tests, "one cannot even claim that the construct is the same in different groups" (Steinmetz, Schmidt, Tina-Booh, Wieczorek, \& Schwartz, 2009, p. 600), a problem that He and van de Vijver (2012) refer to as construct bias ${ }^{1}$ in cross-cultural research.

Motivations for entertainment choices, for instance, are likely to comprise different theoretical components in different cultures (Kim, Seo, Yu, \& Neuendorf, 2014). However, as Kim et al. (2014) point out, the crucial factor of culture has been largely neglected in entertainment research. The majority of research examining entertainment motivations has been confined to one culture only, mostly the USA or a country from Western Europe. The available literature on entertainment motivations is thus focused on "W.E.I.R.D" populations so far. That is, individuals from $W$ estern, Educated, Industrialised, Rich, Developed societies (Heinrich, Heine, \& Norenzayan, 2010, p. 61). Little is known about cross-cultural differences in entertainment motivations (but see Kim et al., 2014). Moreover, the scarce comparative research that is available on this topic typically compares cultures without ensuring that the examined concepts a) actually carry the same meaning, that is, have the same dimensionality across cultures and b) instruments for their assessment are measurement invariant. Assessing the applicability of the measurement of a theoretical concept across 
cultures is an important step towards establishing a broad generalizability and applicability of the theory across these cultures. In other words, extending theories and their associated measurement instruments to other cultures necessitates their measurement invariance across cultures (Steenkamp \& Baumgartner, 1998).

The present study, therefore, is concerned with a test of measurement invariance of a two-factorial entertainment motivation scale (hedonic and eudaimonic motivations) by Oliver and Raney (2011) in samples from Germany and Turkey. More specifically, we examine whether the proposed two-factor structure of the original instrument developed in the US can be validated in samples from other individualistic (German) versus collectivistic (Turkish) societies (Hofstede \& Hofstede, 2005). In other words, by means of a measurement invariance test, we examine whether eudaimonic and hedonic motivations have the same meaning in the two different cultures, that is, whether the factor structure of hedonic and eudaimonic entertainment motivations remains intact as two singular factors as suggested by the US American original.

\section{Hedonic and Eudaimonic Motivations}

Entertainment choices have been at the focus of scholarly attention since the early 1970s and a variety of ideas have been suggested to understand the construct. In the majority of these works the entertainment experience has been conceptualized as fun, pleasure, and thrill (Bosshart \& Macconi, 1998; Vorderer, Klimmt, \& Ritterfeld, 2004) and referred to as hedonic gratifications. However, recent entertainment conceptualizations account for the perception of a deeper meaning or the satisfaction of higher-order needs and label this type of entertainment eudaimonic (Oliver \& Raney, 2011; Wirth, Hofer, \& Schramm, 2012). In the context of the uses and gratifications approach, entertainment was conceptualized as the hedonic type of motive that drives audiences to select media content that promises to satisfy their individual needs. According to this understanding, audiences choose entertainment in 
order to escape from their real lives for a moment, in order to relax and to experience positive affect. A similar argument can be found in the framework of mood management theory (Zillmann, 1988, 2000). This approach holds that individuals seek to maintain and intensify positive moods and, at the same time, diminish and relieve negative ones. According to the theory, one way to do this is by selecting entertaining media content and avoiding hedonically negative media products.

However, to account for the so-called paradox of the enjoyment of sad films (Oliver, 1993; Hofer \& Wirth, 2012), and to elucidate individuals' motivations for experiencing mixed affect, coupled with a desire for deeper meaning and insights into human existence during media exposure, entertainment scholars introduced the notion of eudaimonic entertainment (Oliver \& Bartsch, 2010, 2011; Oliver \& Raney, 2011; Wirth et al., 2012). The term eudaimonia is rooted in Aristotelian philosophy and relates to human potentials and virtues as well as to living according to one's values and one's true potentials (Aristotle, trans. 2002; for a thorough discussion of the concept see Ryff \& Singer, 2008). In positive psychology these concepts were used especially in the context of optimal human psychological functioning and well-being (cf. Kashdan, Biswas-Diener, \& King, 2008). Applying these ideas to media and communication scholarship, Oliver and Raney introduced the notion of eudaimonic entertainment motivations. In contrast and substantial addition to the purely hedonic motivations seeking for joy and pleasure (see above), eudaimonic entertainment motivations reflect a greater need for meaningfulness, introspection, and greater insight into human existence through entertainment consumption. Accordingly, Oliver and Raney presented a two-dimensional concept of entertainment motivations: hedonic and eudaimonic, assuming that audiences consume entertainment not only in the pursuit of hedonic pleasure, but also in the pursuit of an improved understanding of life's purposes and meanings, and that the two motivations are orthogonal. In a series of four studies, Oliver and Raney provided empirical 
evidence for the suggested two-dimensionality of entertainment motivations as well as the affinity of hedonic motivations with pleasant affective states such as fun and enjoyment, and eudaimonic motivations with meaningful affective states such as contemplation and compassion. Whereas hedonic motivations entail the use of rather light-hearted films such as comedies or action movies, eudaimonic motivations entail the use of rather sad, but meaningful films such as Dancer in the Dark or Hotel Rwanda (Oliver \& Hartmann, 2010). Hedonic and eudaimonic entertainment motivations are not mutually exclusive, and audiences may experience both at the same time. The conceptual (and empirical) distinction between the two motivations represents an analytical distinction that emphasizes different underlying needs that can motivate the consumption of media entertainment, highlighting enjoyment/fun, pensive appreciation, or both.

Existing results concerning the two entertainment motivations were predominantly drawn from US American and some Western European samples. In one of the few studies carried out outside the US, Igartua and Barrios (2013) examined the psychometric properties of Oliver and Raney's (2011) scales in Spain and confirmed the proposed two-factor structure, while not explicitly testing invariance of the scales across the cultural contexts. Little is known, therefore, about the validity of the proposed two-dimensionality of entertainment motivations in countries outside the US American or Western European mainstream of communication research. Because Oliver and Raney's (2011) scales appear very promising for research on entertainment consumption, it is worth taking a look at their applicability and generalizability to other cultural contexts.

\section{Cross-Cultural Differences in Entertainment Motivations}

Hedonic and eudaimonic entertainment motivations are likely to differ between different cultures, especially along the dimensions of individualism and collectivism, constituting the most thoroughly researched dimensions of culture in cross-cultural 
communication research (Gudykunst \& Mody, 2002). The emphasis in individualistic societies like the USA or Western European countries is placed on self-fulfillment and selfpreservation. That is, individuals in these societies are guided by principles of agency and achievement, strive for individual success, and attempt to stand out from others and be unique in their lives. Collectivistic societies, by contrast, put a stronger weight on the benefits and welfare of the wider collective. Accordingly, individuals in these societies are more driven by communal goals and loyalty to their in-groups and wider community, prepared to give communal goals precedence over individual ones (Gudykunst \& Bond, 1997; Hofstede, 1991; Kağitçibaşi, 1997; Triandis, 1995, 2001). These cultural orientations have typically been measured either on the aggregate culture-level as a tendency of a whole nation or country, or on the individual level as a personality trait such as idiocentrism versus allocentrism (Triandis, 2001) or independent and interdependent self-construals (Markus \& Kitayama, 1991). Hofstede's (2005) classification of 74 countries in the world into individualistic and collectivistic ones (see also Hofstede, 1991) has been especially influential in this context: Assuming that individualism and collectivism represent the two end-poles on one continuum, countries with high scores on the individualism index, such as the USA, Australia, Great Britain, Canada, and the Netherlands (i.e., the top five countries on Hofstede's individualism index), were characterized as strong advocates of individualistic values, and those with lower scores on the index, such as Guatemala, Ecuador, Panama, Venezuela, Colombia, and Pakistan, were identified as cultures predominantly endorsing collectivistic values.

The relevance of cultural orientations for human psychological functioning and behavior has received empirical support in a large number of studies (Kağitçibaşi, 1997), but only a handful of studies have looked into the relationship between cultural orientations and entertainment motivations. Existing studies studies have typically tended to compare Asian countries (such as China, Korea, or Japan) with the USA, drawing on Hofstede's 
classification (Hofstede et al., 2005). Knobloch, Callison, Chen, Fritzsche, and Zillmann (2005) examined entertainment preferences across Germany, the US, and China. However, their research focus was rather on the uniformity of gender differences across cultures than on cultural differences. Valkenburg and Janssen (1999) compared TV entertainment preferences of US American and Dutch children and found that only the daily viewing times differed between the countries; preferences for entertainment appeared to be highly similar. From an individualism/collectivism point of view, one could argue that these similarities are hardly surprising, as US American and Dutch cultures both constitute examples of highly individualistic societies (see Hofstede's ranking above), and differences should therefore not be expected. But this study also lacked a cultural rationale for its cultural comparison.

In a related study not on entertainment motivation, but on entertainment experiences, Hu and Bartneck (2008) examined differences in the sense of presence, comparing Chinese and Dutch participants during the reception of an interactive movie. Chinese participants exemplified the collectivistic group orientation, Dutch participants the individualistic orientation. An outcome of this study was that the Chinese participants experienced significantly higher amounts of presence than their Dutch comparison group - a finding that could have been predicted based on the kinship between cultural connectedness and experiences of presence. Hu and Bartneck (2008) had not hypothesized this relationship in advance, however, and presented it only as a post-hoc explanation for their findings.

Trepte (2008) approached the topic from a different angle by introducing the notion of "cultural proximity" into her comparative study of entertainment preferences in eight different countries (Austria, China, Germany, Italy, the Netherlands, South Korea, Switzerland, and the USA). Her assumption was that nations with cultural proximity, that is, needs for similar "cultural and historical reference[s] as well as local tastes" (p.1), have a similar affinity to US American prime time fictional programming. Trepte demonstrated that countries resembling 
each other on Hofstede's (1991) individualism/collectivism dimension (among others) were similar in how they evaluated US American television series. At the same time, there was a significant divide of evaluations between Eastern collectivistic countries (China and South Korea) and Western individualistic ones (Austria, Germany, Italy, Netherlands, Switzerland, and the USA).

Kim et al. (2014) compared preferences for entertainment between a Korean and a US American sample, with Korea representing a collectivistic country according to Hofstede's theory, and the US representing an individualistic country. The authors asked participants (1) to name the genre of their three all-time favored films and (2) the affective responses they felt during watching these films. In sum, US participants were more likely than Korean participants to name action films, comedies, and adventure movies as their favorite entertainment. Surprisingly, drama movies that would indicate a rather eudaimonic motivation were equally often named as favorite movies in both groups. However, concerning the retrospective affective responses, Korean participants were more likely to report mixed affective responses than US participants. Finally, Odağ (2013a) compared participants from individualistic and collectivistic societies (again based on Hofstede's theory of culture) with respect to their TV viewing motivations. Participants from collectivistic societies showed higher levels in eudaimonic entertainment motivations than participants from individualistic backgrounds. Hedonic entertainment motivations were largely unaffected by culture.

In summary, culture seems to play a role in entertainment motivations, but little is known about this relationship so far, and even less concerning the distinction between hedonic and eudaimonic entertainment developed by Oliver et al. (2011). Conceptually, however, one may assume that cultural orientations do cause variance in hedonic and eudaimonic entertainment: Individualism is characterized by an emphasis on one's own (rather than one's collective's) happiness, for example, and may consequently entail a greater 
degree of hedonic media pursuit in terms of satisfying one's own immediate needs, among them hedonic entertainment. Collectivism, on the other hand, with its emphasis on the wellbeing of the wider collective, may entail a search for both hedonic and eudaimonic pleasure. Hedonic pleasure is likely to be pursued in this context to the extent that it constitutes a collective goal. Eudaimonic pleasure, one may argue, is directly related to existential human concerns, including the need to belong to a collective, and should therefore be especially prominent in collectivistic societies. These arguments currently remain to a high degree speculative, as only few cross-cultural studies exist that compare the entertainment motivations of audiences from different societies. In addition, none of the above-mentioned studies on cultural differences took the issue of measurement invariance into account. It is, thus, possible that hedonic and eudaimonic entertainment motivations have a different meaning, that is, a different dimensionality and factorial structure, in different cultures, rendering it highly problematic to carry out mean comparisons between them.

\section{Measurement Invariance}

As already mentioned above, whether a construct has the same meaning in different populations (in our case: different cultures) can be assessed by means of measurement invariance tests. One can refer to measurement invariance (or equivalence) when parameters of the measurement model of a latent construct (e.g., factor loadings, item intercepts or item variances) are the same across the respective populations (Kühne, 2013; Steenkamp \& Baumgartner, 1998). In the literature, different forms of measurement equivalence are discussed. The most important forms are configural invariance, metric invariance, and scalar invariance (Kühne, 2013; Steenkamp \& Baumgartner, 1998).

\section{Configural Invariance}

Configural invariance places the least demands on the measurement instrument. It is achieved when the factor structure of a construct is the same across different populations. 
That is, the pattern of salient (i.e., significantly different from zero) and non-salient item loadings has to be the same across groups. The factor loadings do not have to be the same, they just have to be similar. If configural invariance is achieved, one can conclude that the latent construct in question has a similar meaning (i.e., are similarly interpreted) in each population. Configural invariance is a prerequisite of metric invariance (Steinmetz et al., 2009).

\section{Metric Invariance}

This type of invariance is a stricter form of invariance. More precisely, metric invariance requires that the factor loadings do not differ significantly across groups. That is, the factor loading of each item has to be the same for each group. If metric invariance is established, one can conclude that the construct has the same meaning across groups (Steinmetz et al., 2009). That is, the items reflect the same latent construct across different groups. However, the requirement that all loadings have to be the same may be too strict or even unrealistic. Therefore, Byrne, Shavelson, and Muthén (1989) introduced the concept of partial metric invariance. Partial metric invariance is achieved when a subset of factor loadings is the same across groups.

\section{Scalar Invariance}

This type of invariance requires that all (or part of) intercepts of the indicator items are the same across groups. Scalar invariance implies that a latent construct not only has the same meaning, but is also identically scaled across groups (Kühne, 2013). Scalar invariance implies that the differences in the means of the indicator items are only due to the differences in the latent construct. Thus, only if scalar invariance is established one can answer the question whether two populations differ in their means of a latent construct.

The present contribution aims to test measurement invariance of hedonic and eudaimonic motivations for movie/TV consumption across individualistic and collectivistic 
cultures. According to Hofstede and Hofstede (2005), Germany constitutes rank order 18 (indicating the $18^{\text {th }}$ highest score) on the individualism index (i.e., the top third of the index) and thus represents a more individualistic culture (see above). Turkey is ranked number 41 (indicating the $41^{\text {st }}$ highest score) on the index (i.e., located in the second third of the index), and thus constitutes a more collectivistic culture. More precisely, the study tests whether hedonic and eudaimonic entertainment motivations of German and Turkish student samples carry the same meaning (and thus the same factor structure and loadings) across groups. As no study has tested measurement invariance of these two entertainment motivations so far, the present study is the first attempt to examine whether eudaimonic and hedonic motivations have the same meaning across an individualistic and a collectivistic culture. In this, one may assume that the dimensionality of entertainment is the same across the two cultures, that is, hedonic and eudaimonic entertainment yield the same factor structure in both contextsespecially because both entertainment motivations constitute human universals and do not necessarily reflect individualistic versus collectivistic values. At the same time, however, it could be that the two (or either of the two) entertainment dimensions do not form unidimensional concepts in Germany or Turkey and exist only within the boundaries defined by their culture of origin, the USA. Whether or not we find measurement invariance is thus treated as an exploratory research question here.

\section{Method}

We tested measurement invariance with multi-group confirmatory factor analysis (MGCFA) in a structural equation model framework by means of AMOS (Byrne, 2004). Measurement equivalence is a step-wise process. The first step consists of the estimation of a baseline model for the two groups. That is, one has to estimate the hypothesized model for each group simultaneously. In this first model, no invariance constraints are imposed. Configural invariance is achieved if the same pattern of significant factor loadings on latent 
constructs can be observed in both groups. Furthermore, this initial step in testing for equivalence requires a good model fit. In the next steps, constrained models are estimated and compared with this baseline model. Given that the more constrained models are nested within the less constrained models (Schermelleh-Engel, Moosbrugger, \& Müller, 2003) these more constrained models can be compared with the baseline-model by means of a $\chi^{2}$-difference test. A significant difference between two models means that the model with more constraints fits the data worse than the less restrictive model. Hence, the additional parameter restrictions are incorrect. However, the $\chi^{2}$-value has several shortcomings: It is based on the assumption of multivariate normality of the data, it is sensitive to sample size, and it depends on model complexity. Therefore, alternative goodness-of-fit indices have been developed (SchermellehEngel et al., 2003). That is, one can also compare models with descriptive measures of overall model fit, such as the Root Mean Square Error of Approximation (RMSEA, Steiger \& Lind, 1980) or with descriptive measures based on model comparison, such as the Comparative Fit Index (Bentler, 1990). More precisely, the RMSEA is a measure of approximate fit between the empirical and the model-implied covariance structure. Values equal to or less than .05 indicate a good fit of the model. The CFI is a measure to compare the so-called independence model in which all variables are considered to be uncorrelated. Values above .95 indicate and acceptable model-fit (for a thorough overview on model fit in SEM, see Schermelleh-Engel et al., 2003).

\section{Samples and Procedures}

Germany. An online-questionnaire including the hedonic and eudaimonic motivations scale was administered to 209 students from a university in Germany; 180 completed all 12 items and were used for further analyses ( $57 \%$ female; age: $18-31, M=23.26, S D=2.85)$. As an incentive, participants took part in a lottery for gift certificates. 
Turkey. A paper-pencil version of the hedonic and eudaimonic motivations scale was administered to 112 students from universities in Istanbul, Ankara, and Mersin in Turkey. We decided to use a paper-pencil version in Turkey because we wanted to take the "research culture" of the country into account: participating in survey research is still highly uncommon in Turkey, and collecting data in class, by means of an actual questionnaire sheet, and preceded and followed-up by an introduction into the study, made it more likely that students were motivated to participate in the first place. 97 students completed all 12 items and were used for further analyses (69\% female; age: $17-84, M=38.95, S D=16.70)$. Participants were compensated for their efforts with course credit.

\section{Measures}

For the German sample, we used a German translation of the hedonic and eudaimonic motivations scale (see Table 1). Items were rated on a five-point response scale ranging from 1 (completely disagree) to 5 (completely agree). For the Turkish sample, we used a Turkish translation of the scale by Oliver and Raney (2011; see Table 1 for Turkish translations). Items were, again, rated on a five-point response scale ranging from 1 (completely disagree) to 5 (completely agree).

- Insert Table 1 here

Both translations were obtained by means of the committee method in which a number of scholars, fluent in the languages under question, first translated and back-translated items, and subsequently paid special attention to the linguistic and cultural specificities of the German and Turkish populations (Hambleton, 1994; van de Vijver \& Hambleton, 1996). It was against this background that, for data collection in Turkey, we decided to diverge from the focus of the original instrument on movies: In contrast to the USA and Western Europe, 
Turkey can be characterized as a strong $T V$-culture in which especially local movie series constitute the most prominent program of choice (Çakır \& Çakır, 2010; Mutlu, 2008). In order to make sure that both cultural groups under study respond to questionnaire items with respect to their most favourite media format, the translation committee decided to focus the questionnaire items for the Turkish sample on $T V$-programs and those for the German sample on movies (see discussion section for a more critical elaboration of this decision).

\section{Results}

To test for measurement invariance we used AMOS 21.0.0 with maximum likelihood estimation. Before calculating the models, missing data were imputed with the expectation maximization method (Schlomer, Bauman, \& Card, 2010). Little's (1995) test indicated that the missing values were missing completely at random $\left(\operatorname{MCAR}, \chi^{2}(63)=33.94, n s\right)$. We conducted the analysis as follows: In the first step, we estimated a baseline model for each group simultaneously. In this first model, no invariance constraints are imposed. To identify the model, however, we fixed one factor loading to 1 and its intercept to 0 (Kühne, 2013). Configural invariance is achieved if the same pattern of significant factor loadings on latent constructs can be observed in both groups. Furthermore, this initial step in testing for equivalence requires a good model fit. Table 2 displays the fit indices for the models testing measurement invariance. The baseline model (Model 1 in Table 2) showed an acceptable fit. However, in both the hedonic and the eudaimonic motivation subscale two items had to be excluded due to extremely low loadings $(<.30)$. The resulting model is depicted in Figure 1. Bearing in mind these item exclusions, our analysis reveals configural invariance for the hedonic subscale. Factor loadings are depicted in Table 3.

- insert Tables 2 and 3 here 
The second step, testing metric invariance did not yield an acceptable fit. Moreover, the fit was significantly worse than that of the baseline model as the $\chi^{2}$-value increased significantly (see Model 2 in Table 2). However, since the requirement of full metric invariance is likely to be too restrictive (Byrne et al., 1989), only relaxing all factor loading constraints resulted in a non-significant difference compared with the configural model. This procedure yielded equality only for the factor loadings of the hedonic motivation scale across groups (see Model 3 in Table 2). That is, hedonic motivation seems to have the same meaning across cultures. Conversely, we can conclude that the eudaimonic motivation subscale does not have the same meaning across the two cultures.

In the next step, we tested for scalar invariance. Not surprisingly, the full scalar invariance model was significantly worse than the partial metric invariance model as depicted in Table 2 (see Model 4). However, we relaxed the intercept constraints for the eudaimonic item intercepts. The resulting model (Model 5 in Table 2) did not indicate scalar invariance for the hedonic subscale as the $\chi^{2}$-value increased significantly. Thus, for both subscaleshedonic and eudaimonic motivations - scalar invariance was not achieved. The model does not allow us to compare the means of the constructs across cultures. As can be seen in Table 3, all item intercepts differed.

\section{Discussion}

The main aim of this study was to compare the factor structure of Oliver and Raney's (2011) entertainment motivation scale and test its measurement invariance across two samples that represented different cultural orientations on Hofstede's (1991) individualism/collectivism dimension: The first sample was drawn from Germany, representing a more individualistic culture, the second from Turkey, representing a more collectivistic culture. More specifically, the study examined whether hedonic and eudaimonic entertainment motivations, largely conceptualized based on US American samples (Oliver \& 
Raney, 2011), carried the same meaning in a comparably individualistic country from Western Europe (Germany) as well as a more collectivistic country bordering Asia (Turkey). Configural, metric, and scalar invariance of the hedonic and eudaimonic entertainment scales were tested across these countries. Interestingly, while configural invariance (i.e., similar factor loadings of hedonic and eudaimonic motivation subscales across groups) could be secured for both subscales of the entertainment motivation instrument, metric invariance (i.e., lack of significant differences between factor loadings across the two groups) could only be obtained for the hedonic motivation scale. At the same time, the study failed to obtain scalar invariance for both hedonic and eudaimonic entertainment motivations (i.e., equality of intercepts of indicator items on the respective scales) across the two groups. As a corollary, we can conclude that, while the two motivation constructs appear to have something in common (as indicated by their configural invariance), they can by no means be assumed to be the same across the two cultures examined here (as indicated by the lack of metric and scalar invariance, especially with respect to eudaimonic entertainment motivations), rendering any comparison of the constructs across cultures problematic.

Surprisingly, hedonic entertainment motivations appear to be equally interpreted across Germany (representing the more individualistic society) and Turkey (representing the more collectivistic society), pointing to their universal nature across cultural orientations: The motivation to obtain hedonic pleasure and fun from entertainment use appears to be a fundamental human need, that characterizes entertainment consumption in a variety of cultures. At the same time, even with respect to motivations that seem to be so universal, our study alerts to measurement caveats: The fact that hedonic entertainment motivations appear to mean the same in our individualistic and collectivistic example countries does not directly imply that they are identically scaled across these two groups as well (Kühne, 2013). On the 
contrary, our analysis yields that the means of the two samples on the hedonic motivations scale are not comparable.

The comparison aspect seems to be even more difficult with respect to eudaimonic motivations. These entertainment motivations turn out to not even carry the same meaning (i.e., factor structure) across Germany and Turkey, let alone their being identically scaled. Eudaimonic entertainment, therefore, driven by existential questions of life's purposes and the human condition, appears to be conceived differently in the two countries.

A closer look at the literature on eudaimonic well-being may provide an explanation for this difference: Eudaimonic well-being is conceptualized here as a multi-dimensional construct. Ryff and collaborators, for example, presented six dimensions underlying the construct: (1) environmental mastery, (2) autonomy, (3) relatedness, (4) self-acceptance, (5) purpose in life, und (6) personal growth (e.g., Ryff \& Singer, 2006). Even though eudaimonic well-being is different from eudaimonic motivations (the former is a state and the latter a more general disposition), we believe that the more fine-grained dimensions identified in the context of eudaimonic well-being as a state are more clearly identifiable than Oliver and Raney's (2011) one-dimensional conceptualization of eudaimonic entertainment motivations, respectively, as reflecting individualistic versus collectivistic values (Gudykunst \& Bond, 1997; Hofstede, 1991; Kağitçibaşi, 1997; Triandis, 1995, 2001). Autonomy, self-acceptance, and personal growth are clearly in line with agentic goals of self-fulfillment, environmental mastery, and self-preservation that constitute the core of individualistic values. Relatedness, by contrast, resonate the communal emphasis in collectivistic values that aim to benefit and please the wider collective. A multi-dimensional conceptualization of eudaimonic motivations such as this one, even though not directly related to media entertainment but psychological well-being (for an adaptation in the context of media entertainment, see Wirth et al., 2012), could facilitate the development of more specific hypotheses concerning the interplay 
between cultures (individualistic/collectivistic) and eudaimonic entertainment motivation (self-driven vs. collective-driven) - something that was beyond the scope of the present paper and needs to be left to future studies.

Taken together, our study undeniably calls for an emic approach to entertainment motivations (see Berry, Poortinga, Breugelmans, Chasiotis, \& Sam, 2011 for a description of the term emic): In the present paper, we pursued an etic approach to comparing entertainment motivations across cultures by assuming that the hedonic and eudaimonic entertainment scale can be universally applied (see Berry et al., 2011, for the term etic). The latter is a very strong claim, however, and even Oliver and Raney (2011) put this claim into perspective with regard to their US based sample. An emic approach, by contrast, requires to start conceptualizing entertainment motivation constructs from within the cultures under question (by means of open-ended qualitative methods of data collection and analysis), develop indigenous items and scales, and only subsequently validate them in the respective culture (using indicators such as criterion, concurrent, convergent, and discriminant validity). As a result of such an approach, entertainment may indeed have a factor structure that deviates from the Oliver and Raney (2011) original. Such an approach would also help to clarify whether the differences in entertainment motivations we find across cultures are a reflection of differences in the motivations themselves or a side-effect of the type of media messages that are offered in the respective cultures to satisfy these motivations. Believing in the universality of human motivations, the latter appears more plausible to us.

\section{Limitations and Strengths}

Needless to say, our study has a number of limitations that may narrow the conclusions we can draw from it and call for more research. Some of these are more methodological in nature, others more conceptual. A methodological delimitation of our study is first of all our choice to only remedy the construct bias in cross-cultural entertainment 
research. In the present study, other types of bias, such as method and item bias, were not examined. The method bias comprises issues that may arise from sampling as well as the instrument and its administration. In our study, for example, while we can be confident that the two university samples are more comparable than convenience samples with regards to education, they can by no means count as comparable with respect to age: The age range of the Turkish sample (17 to 84$)$ is considerably wider than that of the German sample (18 to 21 ), most likely due to the fact that one of the seminars in which data were collected in Mersin was open to a wider public taking part in community education. The Turkish sample thus includes a minimum of three generations - generations that have been shown to differ in regards to entertainment motivations and should thus not be averaged to an aggregate score (Akman \& Mishra, 2010; Mares \& Sun, 2010). Nor can the student samples count as representative of the underlying German or Turkish population. In other words, the two samples may not constitute a good-enough basis to draw conclusions about entertainment motivations in Germany and Turkey as a whole. At the same time, we believe that student samples are better suited to carry out comparisons between cultures than more representative country samples, precisely because students represent a homogenous group that are comparable with respect to demographic characteristics such as educational background, socioeconomic status, etc. Comparing more representative non-convenience, random samples may in fact introduce bias with respect to such characteristics, especially because they are likely to be unevenly distributed across countries/cultures. Student samples allow for a better comparability in this case. On the other hand, because we are relying on student samples, we admit that our samples were more W.E.I.R.D. than not in Heinrich et al.'s (2010) sense of the word (see above). In addition, our samples were small (especially our Turkish sample with an $n$ of 97) and comprised a higher number of female participants (Turkey: 57\%; Germany: $69 \%$ ). Biological sex has been shown to influence entertainment preferences and may have 
affected our results, too (Odağ, 2013b; Oliver, Sargent, \& Weaver, 1998). These shortcomings will have to be addressed in future studies.

Item bias is another source of error that has not been fully scrutinized in the present study, comprising issues of translation, item meaning, formatting, grammar/phrasing, and cultural appropriateness/relevance of translated items. While translations of the hedonic and eudaimonic entertainment motivations scale into German and Turkish were each achieved with great rigour (making sure that translation standards are met), we still have little evidence that translations are actually comparable. This is further obscured by the fact that the items in the German and Turkish versions focused on slightly different things: movies in the German version and $T V$ programs in the Turkish version (see Table 1). As highlighted in the methods section of this paper, this difference in phrasing goes back to differences in the consumption culture of the two countries, with Turkish audiences preferring to watch fictional content on TV (Çakır \& Çakır, 2010; Mutlu, 2008), and German audiences preferring to watch movies by means of a larger variety of media (such as DVD, the Internet, and cinema theatres; e.g., Presseportal, 2015). Our comparative study took these differences into account by emphasizing various consumption cultures in the survey questionnaire. Presenting either TV programs or movies across both countries would have introduced a cultural bias in data collection. Whether the resulting differences between cultures as identified by our measurement invariance tests can be traced back to cross-cultural variations in the examined entertainment concepts or the different media products (movies versus TV programs) as specified in the items, need remain a matter of speculation at this point. We have strong reason to believe that this bias in our study is negligible, however, since the programs watched most frequently on Turkish TV are in fact movie series (see http://www.medyafaresi.com/haber/18-Subat-2015-Carsamba-TV-reytingleri_455621.html for a scaling of current viewing frequencies of TV programs on Turkish television). Still, 
more studies are clearly needed to remedy the potential method and item biases inherent in the present work.

Among the more conceptual limitations of our study are issues surrounding Hofstede's individualism and collectivism constructs (Hofstede \& Hofstede, 2005). Firstly, Hofstede's data collection started in 1967, and more up-to-date data are presently missing. Although cultural changes might occur very slowly, the availability of entertainment media all over the world, the European Union enlargement including Turkey as a candidate country, special circumstances with regard to migration flows (i.e., migration of Turkish guest workers to Germany and their return migration to Turkey), may rightfully raise doubts about the legitimacy of comparing Germany and Turkey as typical representatives of individualistic and collectivistic cultures, and investigate their differences in the context of entertainment motivations. The present study is insufficient for drawing conclusions about Hofstede's individualism/collectivism dimension, and further studies including a larger number of example countries are needed to remedy this shortcoming. In addition, one may ask why Germany and Turkey are selected as exemplifying individualism and collectivism, while the countries may differ (or be similar) on a number of other dimensions that were not looked into here. As indicated above, the individualism/collectivism distinction is not the only one on which cultures may differ, yet it has been the one most widely used in cross-cultural communication scholarship (Gudykunst \& Lee, 2002). Other dimensions of cross-cultural variability are equally promising, especially in the context of a comparison between Germany and Turkey: for example, uncertainty avoidance (Hofstede \& Hofstede, 2005, p. 168f.; Germany: rank order 65, Turkey: rank order 23-25), and power distance (Hofstede \& Hofstede, 2005, p.43f.; Germany: rank order 63-65, Turkey: rank order 32-33). Equally important may be religion, which also differs between Germany (representing an essentially Christian religion) and Turkey (representing an essentially Muslim religion). To tie our study 
in with other studies in media and communication research, we concentrated here on the individualism/collectivism distinction only. A discussion of media entertainment against the backdrop of other cultural dimensions was beyond the scope of this paper. Similarly, one may ask why Turkey and Germany were selected in the first place. This selection was a pragmatic one, related to the cultural backgrounds of the authors of the present paper. It is obvious that further countries need to be taken into account in future studies - our study constitutes only a first step.

Secondly, more recent literature questions the one-dimensionality of individualism vs. collectivism, and presents alternative, multi-dimensional approaches to cultural dimensions, including the 16-item Horizontal-Vertical Individualism-Collectivism scale (Triandis \& Gelfand, 1998) or the multidimensional Personal Cultural Orientations scale (Sharma, 2010). Thirdly, Hofstede's data collection focused on work-oriented values, as the primary aim of Hofstede's (1991) studies was to look at the interstices of national and organizational cultures at numerous subsidiaries of the multinational company IBM by conducting survey research with over 100,000 participants from a wide variety of countries. As a corollary, the type of individualism and collectivism that Hofstede discovered is applicable to comparisons concerning occupational, organizational, and management issues. However, with regard to leisure time activities including entertainment media reception, it might be useful to draw on more general value models operationalized in measures like the Schwartz Value Survey (e.g., Schwartz, 1992), the Portrait Values Questionnaire (e.g., Schwartz et al., 2001), or the Rokeach Value Survey (Rokeach, 1967). Fourthly, Hofstede's individualism/collectivism distinction is based on an aggregate, country-level analysis. Researchers like Gudykunst and Lee (2002) have called for a more fine-grained, individual-level analysis instead, or at least in addition, to crude country-level differentiations, taking into account that there may also be large cultural variation within cultures or countries. One way to address this would be to 
measure the level of individualism or collectivism within the samples by means of individuallevel constructs such as idiocentrism versus allocentrism (Triandis, 2001) or independent and interdependent self-construals (Markus \& Kitayama, 1991).

Finally, little is currently known concerning the measurement equivalence of the Hofstede scales measuring individualism/collectivism. As this study underlines, however, cross-cultural comparisons without securing measurement invariance are based on untested, and often unwarranted, methodological assumptions.

Despite the limitations of the present study, several new insights about cross-cultural (in)variance of hedonic and eudaimonic entertainment motivations render the study worthwhile: First of all, our study is among the very few in media and communication research that have launched a cross-cultural comparison and included theoretical assumptions (i.e., individualism/collectivism) about whether or not cultures might differ in their entertainment motivations (e.g., Kim et al., 2014). Apart from that, it is the first study that pays attention to the distinction between hedonic and eudaimonic motivations and tested measurement invariance of Oliver and Raney's (2011) scale. The two major results - a) hedonic entertainment motivations appear to constitute universal motivations and $b$ ) eudaimonic entertainment motivations appear to cross-culturally differ - clearly indicate that future studies should investigate eudaimonic entertainment motivations by taking specific cultural characteristics into account. Especially, the distinction between individualism and collectivism seems to be a useful theoretical background for future research. Most importantly, however, our study has effectively demonstrated that instruments developed in one part of the world cannot simply be used for comparison in another part of the world without being tested for equivalence of the underlying concepts. A cross-cultural comparison like that is bound to yield nonsensical evidence at best. 


\section{References}

Akman, I., \& Mishra, A. (2010). Gender, age and income differences in internet usage among employees in organizations. Computers in Human Behavior, 26(3), 482-490.

Aristotle. (2002). Nicomachean ethics. (Rowe, C., \& Broadie, S., Eds. \& Trans.). Oxford, UK: Oxford University Press..

Bentler, P. M. (1990). Comparative fit indexes in structural models. Psychological Bulletin, $107,238-246$.

Berry, J. W., Poortinga, Y. H., Breugelmans, S. M., Chasiotis, A., \& Sam, D., L. (2011).

Cross-cultural psychology. Research and applications (3rd ed.). Cambridge, UK: Cambridge University Press.

Bosshart, L., \& Macconi, I. (1998). Media Entertainment. Communication Research Trends $18(3), 3-8$.

Byrne, B. M. (2004). Testing for multigroup invariance using AMOS Graphics: A road less traveled. Structural Equation Modeling, 11, 272-300. doi:10.1207/s15328007sem1102_8

Byrne, B. M., Shavelson, R. J., \& Muthén, B. (1989). Testing for the equivalence of factor covariance and mean structures: The issue of partial measurement invariance. Psychological Bulletin, 105, 456-466. doi:10.1037//0033-2909.105.3.456

Çakır, V. \& Çakır, V., (2010). Televizyon Bă̆ımlılı̆̆ı. Konya: Literatürk Yayinlari.

Gudykunst, W. B., \& Bond, M. H. (1997). Intergroup relations across cultures. In J. W. Berry, M. H. Segall, \& Ç. Kağitçibaşi (Eds.), Handbook of cross-cultural psychology: Vol. 3. Social behavior and applications (2nd ed., pp. 119-161). Needham Heights, MA: Allyn \& Bacon. 
Gudykunst, W. B., \& Lee, C. M. (2002). Cross-cultural communication theories. In W. B. Gudykunst \& B. Mody (Eds.), Handbook of international and intercultural communication (pp. 25-50). Thousand Oaks, CA: Sage.

Gudykunst, W. B., \& Mody, B. (Eds.). (2002). Handbook of international and intercultural communication (2nd ed.). Thousand Oaks, CA: Sage.

Hambleton, R. K. (1994). Guidelines for adapting educational and psychological tests: a progress report. European Journal of Psychological Assessment, 10, 229-244.

He, J., \& van de Vijver, F. J. R. (2012). Bias and equivalence in cross-cultural research. Online Readings in Psychology and Culture, 2(2). doi:10.9707/2307-0919.1111

Heinrich, J., Heine, S. J., \& Norenzayan, A. (2010). The weirdest people in the world? Behavioral and Brain Sciences, 33(1), 61-135.

Hofer, M., \& Wirth, W. (2012). It's right to be sad: The role of meta-appraisals in the sadfilm paradox - a multiple mediator model. Journal of Media Psychology, 24, 43-54. doi:10.1027/1864-1105/a000061

Hofstede, G. (1991). Cultures and organizations: Software of the mind. New York, NY: McGraw-Hill.

Hofstede, G., \& Hofstede, G. J. (2005). Cultures and organizations: Software of the mind (2nd ed.). New York, NY: McGraw-Hill.

Hu, J., \& Bartneck, C. (2008). Culture matters: A study on presence in an interactive movie. CyberPsychology \& Behavior, 11, 529-535. doi: 10.1089/cpb.2007.0093

Igartua, J.-J., \& Barrios, I. (2013). Hedonic and eudaimonic motives for watching feature films. Validation of the Spanish version of Oliver \& Raney's scale. Communications: The European Journal of Communication Research, 38(4), 411-431. doi:

10.1515/commun-2013-0024 
Kağitçibaşi, Ç. (1997). Individualism and collectivism. In J. W. Berry, M. H. Segall, \& Ç. Kağitçibaşi (Eds.), Handbook of cross-cultural psychology: Vol. 3. Social behavior and applications (2nd ed., pp. 1-50). Needham Heights, MA: Allyn \& Bacon.

Kashdan, T. B., Biswas-Diener, R., \& King, L. A. (2008). Reconsidering happiness: the costs of distinguishing between hedonics and eudaimonia. The Journal of Positive Psychology, 3, 219-233. doi:10.1080/17439760802303044

Kim, J., Seo, M., Yu, H., \& Neuendorf, K. (2014). Cultural differences in preference for entertainment messages that induce mixed responses of joy and sorrow. Human Communication Research, 40, 530-552. doi:10.1111/hcre.12037

Knobloch, S., Callison, C., Chen, L., Fritzsche, A., \& Zillmann, D. (2005). Children's sexstereotyped self-socialization through selective exposure to entertainment: Crosscultural experiments in Germany, China, and the United States. Journal of Communication, 55, 122-138. doi:10.1111/j.1460-2466.2005.tb02662.x

Kühne, R. (2013). Testing measurement invariance in media psychological research. Journal of Media Psychology, 25, 153-159. doi:10.1027/1864-1105/a000096

Little, R. J. (1995). Modeling the drop-out mechanism in repeated-measures studies. Journal of the American Statistical Association, 90, 1112-1121. doi:10.1080/01621459.1995.10476615

Mares, M. L., \& Sun, Y. (2010). The multiple meanings of age for television content preferences. Human Communication Research, 36, 372-396. doi:10.1111/j.14682958.2010.01380.x

Markus, H. R., \& Kitayama, S. (1991). Culture and self: Implications for cognition, emotion, and motivation. Psychological Review, 98, 224-253. doi:10.1037//0033295X.98.2.224

Mutlu, E., (2008). Televizyonu Anlamak. Ankara: Ayraç Yayinlari. 
Odağ, Ö. (2013a, September). (Ethnic) identities and media uses and gratifications - what is the story? Paper presented at the $8^{\text {th }}$ Conference of the Media Psychology Division of the German Psychological Association, Würzburg, Germany.

Odağ, Ö. (2013b). Experiences and emotions in literary reception: do men and women differ? Cognition \& Emotion, 27(5), 856-874. doi:10.1080/02699931.2012.751359

Oliver, M. B. (1993). Exploring the paradox of the enjoyment of sad films. Human Communication Research, 19, 315-342. doi:10.1111/j.1468-2958.1993.tb00304.x

Oliver, M. B., \& Bartsch, A. (2010). Appreciation as audience response: Exploring entertainment gratifications beyond hedonism. Human Communication Research, 36, 53-81. doi: 10.1111/j.1468-2958.2009.01368.x

Oliver, M. B., \& Bartsch, A. (2011). Appreciation of entertainment: The importance of meaningfulness via virtue and wisdom. Journal of Media Psychology, 23, 29-33. doi:10.1027/1864-1105/a000029

Oliver, M. B., \& Hartmann, T. (2010). Exploring the role of meaningful experiences in users' appreciation of "good movies". Projections, 4, 128-150. doi:10.3167/proj.2010.040208

Oliver, M. B., \& Raney, A. A. (2011). Entertainment as pleasurable and meaningful: Identifying hedonic and eudaimonic motivations for entertainment consumption. Journal of Communication, 61, 984-1004. doi:10.1111/j.1460-2466.2011.01585.x

Oliver, M. B., Sargent, S., \& Weaver, J. B. (1998). The impact of sex and gender-role selfperception on affective reactions to different types of film. Sex Roles, 38, 45-62.

Presseportal (2015). Retrieved from http://www.presseportal.de/pm/107460/3032093.

Rokeach, M. (1967). The Rokeach value survey. Sunnydale, CA: Halgren Tests.

Ryff, C. D., \& Singer, B. H. (2006). Best news yet on the six-factor model of well-being. Social Science Research, 35, 1103-1119. doi:10.1016/j.ssresearch.2006.01.002 
Ryff, C. D., \& Singer, B. H. (2008). Know thyself and become what you are: A eudaimonic approach to psychological well-being. Journal of Happiness Studies, 9, 13-39. doi:10.1007/s10902-006-9019-0

Schermelleh-Engel, K., Moosbrugger, H., \& Müller, H. (2003). Evaluating the fit of structural equation models: Tests of significance and descriptive goodness-of-fit measures. Methods of psychological research online, 8, 23-74.

Schlomer, G. L., Bauman, S., \& Card, N. A. (2010). Best practices for missing data management in counseling psychology. Journal of Counseling Psychology, 57, 1-10. doi:10.1037/a0018082

Schwartz, S. H. (1992). Universals in the content and structure of values: Theoretical advances and empirical tests in 20 countries. In M. P. Zanna (Ed.), Advances in experimental social psychology, Vol. 25 (pp. 1-65). San Diego, CA: Academic Press.

Schwartz, S. H., Melech, G., Lehmann, A., Burgess, S., Harris, M., \& Owens, V. (2001). Extending the cross-cultural validity of the theory of basic human values with a different method of measurement. Journal of Cross-Cultural Psychology, 32, 519542. doi:10.1177/0022022101032005001

Sharma, P. (2010). Measuring personal cultural orientations: Scale development and validation. Journal of the Academy of Marketing Science, 38, 787-806. doi:10.1007/s11747-009-0184-7

Steenkamp, J., \& Baumgartner, H. (1998). Assessing measurement invariance in crossnational consumer research. Journal of Consumer Research, 25, 78-90. doi: $10.1086 / 209528$

Steiger, J. H., \& Lind, J. C. (1980, May). Statistically-based tests for the number of common factors. Handout for a presentation delivered at the meeting of the Psychometric Society, Iowa City, I A. 
Steinmetz, H., Schmidt, P., Tina-Booh, A., Wieczorek, S., \& Schwartz, S. H. (2009). Testing measurement invariance using multigroup CFA: Differences between educational groups in human values measurement. Quality \& Quantity, 43, 599-616. doi:10.1007/s11135-007-9143-x

Trepte, S. (2008). Cultural proximity in TV entertainment: An eight-country study on the relationship of nationality and the evaluation of U.S. prime-time fiction. Communications, 33, 1-26. doi: 10.1515/commun.2008.001

Triandis, H. C. (1995). Individualism and collectivism. Boulder, CO: Westview.

Triandis, H. C. (2001). Individualism and collectivism. In D. Matsumoto (Ed.), Handbook of culture and psychology. New York, NY: Oxford University Press.

Triandis, H. C., \& Gelfand, M. J. (1998). Converging measurement of horizontal and vertical individualism and collectivism. Journal of Personality and Social Psychology, 74, 118-128. doi:10.1037/0022-3514.74.1.118

Valkenburg, P. M., \& Janssen, S. C. (1999). What do children value in entertainment programs? A cross-cultural investigation. Journal of Communication, 49, 3-21. doi:10.1111/j.1460-2466.1999.tb02790.x

Van de Vijver, F. J. R., \& Hambleton, R. K. (1996). Translating tests: some practical guidelines. European Psychologist, 1, 89-99.

Vorderer, P., Klimmt, C., \& Ritterfeld, U. (2004). Enjoyment: At the heart of media entertainment. Communication theory, 14(4), 388-408.

Wirth, W., Hofer, M., \& Schramm, H. (2012). Beyond pleasure: Exploring the eudaimonic entertainment experience. Human Communication Research, 38, 406-428. doi: 10.1111/j.1468-2958.2012.01434.x

Zillmann, D. (1988). Mood management through communication choices. American Behavioral Scientist, 31, 327-340. doi:10.1177/000276488031003005 
Zillmann, D. (2000). Mood management in the context of selective exposure theory. In M. E. Roloff (Ed.), Communication yearbook (Vol. 23, pp. 103-123). Thousand Oaks, CA: Sage. 


\section{Footnotes}

${ }^{1}$ Among other types of bias such as method bias (arising from sampling, the instrument, and/or its administration procedure) and item bias (arising from different meanings of single items across cultural groups; He \& van de Vijver, 2012).

${ }^{2}$ For a visualization of these scores see selected world maps online such as http:/www.clearlycultural.com/geert-hofstede-cultural-dimensions/individualism/ 


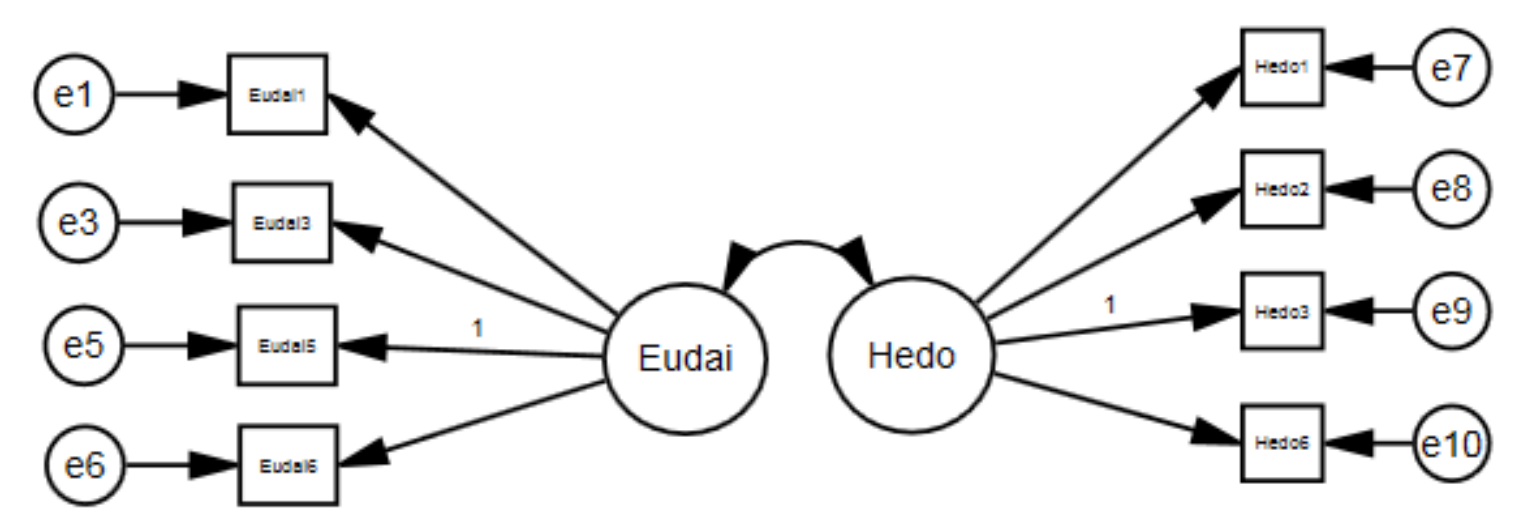

Figure 1. Baseline model of eudaimonic and hedonic motivation. 
Table 1

Eudaimonic and hedonic entertainment motivation items

Item name Item text English (original) I like films/TV programs that challenge my way

Eudai1 of seeing the world.

I am very moved by films/TV programs that are

Eudai2

Eudai3

Eudai4

Eudai5

Eudai6

\begin{abstract}
about people's search for greater understanding
\end{abstract}
in life.

I like films/TV programs that make me more reflective.

I like films/TV programs that have profound meanings or messages to convey.

My favorite kinds of films/TV programs are ones that make me think.

I like films/TV programs that focus on meaningful human conditions.
Item text Turkish

Benim dünya görüşüme meydan okuyup

geliştiren TV programlarını izlemekten

hoşlanıyorum.

İnsanların hayatı daha iyi anlamak için arayışları Filme, die Menschen zeigen, die auf der Suche

hakkındaki programlar beni çok

heyecanlandiriyor.

Beni daha düşünceli yapan TV programlarını

seyretmekten hoşlanıyorum.

Yaşama dair derin anlamları ve mesajları ileten

TV programlarını seyretmekten hoşlanırım.

Benim için favori TV programları beni

düşündüren programlar.

Anlamlı insan halleri, koşulları üzerine

odaklaşan TV programlarını izlemekten
Item text German

Ich mag Filme, die die Art wie ich die Welt

sehe, in Frage stellen

nach dem Sinn des Lebens, sind finde ich sehr

bewegend.

Ich mag Filme, die mich zum Nachdenken

bringen.

Ich mag Filme, die das Spektrum menschlicher

Schicksale und Gefühle zeigen.

Meine Lieblingsfilme sind solche, die mich zum

Nachdenken anregen.

Ich mag Filme, die einen tieferen Sinn haben

oder eine tiefgründige Aussage vermitteln. 
hoşlanıyorum.

I find that even simple films/TV programs can

Eğlenceli oldukları sürece basit TV

be enjoyable as long as they are fun.

It's important to me that I have fun when

watching a film/TV program.

Films/TV programs that make me laugh are

among my favorites.

I like films/TV programs that may be considered

Hedo4 "silly" or "shallow" if they can make me laugh and have a good time.

My favorite kinds of films/TV programs are

Hedo5 happy and positive.

For me, the best films/TV programs are ones programlarını bile seyretmekten hoşlanırım.

\section{Benim için televizyon programı izlerken}

eğlenebilmek önemlidir.

Beni güldüren TV programları favorilerim

arasındadır.

Saçma ya da sığ olarak düşünülen TV

programlarını eğer beni güldürüyorlarsa ve iyi vakit geçirmemi sağliyorlarsa izlemekten hoșlanırım.

Benim favori TV program türlerim mutlu ve pozitif olanlar.

Benim için en iyi TV programları beni

eğlendiren programlar.
Ich finde, dass selbst einfältige Filme

unterhaltsam sein können, solange sie lustig

sind.

Es ist wichtig für mich, Spaß zu haben während ich einen Film schaue.

Filme, die mich zum Lachen bringen, sind mir die liebsten.

Ich mag Filme, die vielleicht als „dumm“ oder „flach" bezeichnet werden, solange sie mich zum Lachen bringen und ich eine gute Zeit habe während ich sie schaue.

Meine Lieblingsfilme sind fröhlich und positiv.

Für mich sind die besten Filme die, die mich unterhalten 
Table 2

Model comparison: Impact of invariance constraints on model fit (3items)

\begin{tabular}{|c|c|c|c|c|c|c|c|c|c|}
\hline Model & Compared Model & $\chi^{2}$ & $d f$ & $\chi^{2} / d f$ & CFI & RMSEA & $\Delta \chi^{2}$ & $\Delta d f$ & $p$ \\
\hline Model 1: unconstrained, i.e., no invariance constraints & & 60.42 & 38 & 1.59 & .96 & .04 & - & - & - \\
\hline Model 2: factor loadings constrained, i.e., full metric invariance & Model 1 & 79.84 & 44 & 1.81 & .94 & .05 & 19.42 & 6 & $<.01$ \\
\hline Model 3: metric invariance of hedonic entertainment & Model 1 & 66.62 & 41 & 1.62 & .96 & .04 & 6.20 & 3 & $n s$ \\
\hline Model 4: Full scalar invariance & Model 3 & 208.19 & 51 & 4.08 & .66 & .12 & 141.56 & 10 & $<.001$ \\
\hline Model 5: Scalar invariance of hedonic motivations & Model 3 & 184.65 & 45 & 4.10 & .78 & .10 & 118.03 & 4 & $<.001$ \\
\hline
\end{tabular}


Table 3

Comparison of factor loadings across cultures

\begin{tabular}{|c|c|c|c|c|c|}
\hline \multirow[b]{2}{*}{ Subscale } & \multirow[b]{2}{*}{ Item } & \multicolumn{2}{|c|}{ Turkey } & \multicolumn{2}{|c|}{ Germany } \\
\hline & & Loading & Intercept & Loading & Intercept \\
\hline \multirow[t]{4}{*}{ Eudaimonic Motivation } & Eudai1 & $0.65^{\mathrm{a}}$ & $1.09^{\mathrm{a}}$ & $0.96^{\mathrm{b}}$ & $0.33^{b}$ \\
\hline & Eudai3 & $1.64^{\mathrm{a}}$ & $-2.27^{\mathrm{a}}$ & $0.87^{\mathrm{b}}$ & $0.78^{\mathrm{b}}$ \\
\hline & Eudai5* & 1.00 & 0.00 & 1.00 & 0.00 \\
\hline & Eudai6 & $0.67^{\mathrm{a}}$ & $1.10^{\mathrm{a}}$ & $0.83^{b}$ & $0.78^{\mathrm{b}}$ \\
\hline \multirow[t]{4}{*}{ Hedonic Motivation } & Hedo1 & 1.30 & $-2.00^{\mathrm{a}}$ & 0.76 & $1.26^{\mathrm{b}}$ \\
\hline & Hedo2 & 0.98 & $-0.22^{\mathrm{a}}$ & 0.90 & $0.81^{\mathrm{b}}$ \\
\hline & Hedo3* & 1.00 & 0.00 & 1.00 & 0.00 \\
\hline & Hedo6 & 1.81 & $-3.39^{\mathrm{a}}$ & 1.07 & $-0.22^{\mathrm{b}}$ \\
\hline
\end{tabular}

Note. Factor loadings are unstandardized values. Different superscripts in a row indicate significant differences across cultures

* Items Eud5 and Hed3 are restricted to unity to identify the measurement model. These items are not subject to the invariance test. 